\title{
Preparation of Wear-Resistant Coating on Ti6Al4V Alloy by Cold Spraying and Plasma Electrolytic Oxidation
}

\author{
Mingzeng Shao ${ }^{1, *}$, Wei Wang ${ }^{1,2} \mathbb{D}$, Hongbo Yang ${ }^{1,2}$, Xueer Zhang ${ }^{1}$ and Xiaomei He ${ }^{1}$ \\ 1 School of Metallurgical Engineering, Xi'an University of Architecture and Technology, Xi'an 710055, China; \\ gackmol@163.com (W.W.); yanghongbo_0413@126.com (H.Y.); zxe991104@jiugang.com (X.Z.); \\ hxmei1980@126.com (X.H.) \\ 2 Shaanxi Engineering Research Center of Metallurgical, Xi'an University of Architecture and Technology, \\ Xi' an 710055, China \\ * Correspondence: smz516@163.com; Tel.: +86-029-82202938
}

check for updates

Citation: Shao, M.; Wang, W.; Yang, H.; Zhang, X.; He, X. Preparation of Wear-Resistant Coating on Ti6Al4V Alloy by Cold Spraying and Plasma Electrolytic Oxidation. Coatings 2021, 11, 1288. https://doi.org/10.3390/ coatings11111288

Academic Editor: Juozas Padgurskas

Received: 21 September 2021

Accepted: 19 October 2021

Published: 23 October 2021

Publisher's Note: MDPI stays neutral with regard to jurisdictional claims in published maps and institutional affiliations.

Copyright: (c) 2021 by the authors. Licensee MDPI, Basel, Switzerland. This article is an open access article distributed under the terms and conditions of the Creative Commons Attribution (CC BY) license (https:/ / creativecommons.org/licenses/by/ $4.0 /)$.

\begin{abstract}
In order to improve the wear resistance of Ti6Al4V alloy, the alloy was first coated with alumina-reinforced aluminum coating (CS-coating) by cold spraying, and then the alloy with CScoating was processed by plasma electrolytic oxidation (PEO) under unipolar mode and soft sparking mode, respectively, to prepare wear-resistant PEO coatings. For comparison, Ti6Al4V alloy without CS-coating was also subjected to PEO treatment. The microstructure, phase composition, hardness, and wear resistance of the PEO coatings formed on Ti6Al4V alloy with and without CS-coating were investigated. The results revealed that PEO coatings formed on Ti6Al4V alloy with CS-coating under soft sparking mode contained more $\alpha-\mathrm{Al}_{2} \mathrm{O}_{3}$, possessed larger thickness, more compact microstructure, and higher microhardness than that formed under unipolar mode. The PEO coating formed on Ti6Al4V substrate was mainly composed of $\mathrm{TiO}_{2}$ and had pores and cracks. Among all these coatings, PEO coating formed on Ti6Al4V alloy with CS-coating under soft sparking mode exhibited the best wear resistance with a wear rate of $1.18 \times 10^{-5} \mathrm{~mm}^{3} /(\mathrm{Nm})$, which was only $15.28 \%$ of that of the Ti6Al4V substrate. The investigation indicated that the combination of cold spraying and PEO under soft sparking mode is a promising technique for improving the wear resistance of titanium alloy.
\end{abstract}

Keywords: titanium alloy; cold spray; plasma electrolytic oxidation; soft sparking

\section{Introduction}

Ti6Al4V is widely used in the manufacture of airplane components due to its low density, high strength, and excellent corrosion resistance [1]. Some Ti6Al4V components such as landing gears, flaps slide rails, and hatch-door hinges are subjected to relative movement. This circumstance always causes failures of the Ti6Al4V components due to its low hardness and poor wear resistance [2]. A large number of technologies were used to improve the wear resistance of Ti6Al4V alloy, such as laser-clad [3], laser shock pack cementation [4], magnetron sputtering [5], and plasma electrolytic oxidation [6,7]. Among the surface modification techniques, PEO is a promising novel process due to its environmentally friendly and economically efficient nature. It has been widely used to process valve metals, such as $\mathrm{Al}, \mathrm{Mg}, \mathrm{Ti}, \mathrm{Zr}$, and their alloys, to form ceramic coatings that can improve their surface performances [8].

However, it should be mentioned that the wear resistance of the PEO coatings formed on titanium alloys is not as good as that formed on aluminum alloys and is not sufficient for many harsh service conditions. The PEO coatings formed on Titanium alloys usually have a hardness of less than $700 \mathrm{HV}$ as they are mainly composed of $\mathrm{TiO}_{2}$ [9]. Furthermore, pores and thermal cracks are usually present in the PEO coatings, which reduce the load bearing capacity of the coatings [10-12]. However, for aluminum alloys, their PEO coatings are mainly composed of $\mathrm{Al}_{2} \mathrm{O}_{3}$ phases which have a higher hardness and stability than 
$\mathrm{TiO}_{2}$ [13]. In addition, during the PEO process of aluminum, a soft sparking regime can be established by using a bipolar current mode, where the ratio of positive to negative charge quantities $(Q p / Q n)$ is lower than one $[14,15]$. It has been reported that PEO under soft sparking regime is very convenient for achieving compact coatings on $\mathrm{Al}$ alloys with good wear performance [16].

In light of the above, some combined methods were developed in which the titanium or titanium alloy was coated with aluminum coating and then the aluminum coating was subjected to PEO treatment. Koshuro $[17,18]$ prepared alumina coatings on VT6 titanium alloy by thermal spraying, with further PEO processing at different current densities. Kang [19] studied the wear performance of the duplex coatings produced on Ti6Al4V alloy by a combined method of magnetron sputtering and PEO in different electrolytes. Hu [20] modified the surface of titanium by hot dip aluminizing followed by PEO treatment at different durations. It was reported that the wear resistance of titanium and its alloys can be considerably improved by these combined methods. However, there are some defects in the implementation of these combined methods for preparing aluminum coating. For the hot dipping and thermal spraying treatment, the temperature of the base alloy can rise to as high as $500^{\circ} \mathrm{C}$, which may lead to the phase transformation of titanium alloys. For the magnetron sputtering treatment, the equipment is expensive, and the thickness of the prepared aluminum coating is limited. Therefore, it is necessary to look for an alternative technology to prepare aluminum coatings on titanium alloy with lower cost and lower processing temperature in a simplified process. Cold spraying is a relatively new material deposition technique with lower processing temperatures than thermal spraying techniques. In the cold spraying process, metallic particles are accelerated by supersonic gas flow and then deposited on the substrate [21]. The coatings deposited by cold spraying technology demonstrate low residual stresses and compact structure. This technology is ideally suitable for depositing Al coatings on different substrates [22,23]. However, few studies can be found on the PEO of cold sprayed coatings on titanium alloy, especially under soft sparking mode.

In this study, Ti6Al4V alloy was first coated with alumina-reinforced aluminum coating by cold spraying and then the alloy was processed by PEO under unipolar mode and soft sparking mode, respectively, to prepare wear-resistant coatings. For comparison, Ti6Al4V alloy without CS-coating was also subjected to PEO treatment. The growth characteristic, microstructure, phase composition, and hardness of the PEO coatings were investigated, and the wear resistance of the PEO coatings was tested.

\section{Materials and Methods}

\subsection{Materials}

Ti6Al4V alloy was used as the substrate with the nominal chemical composition presented in Table 1. Alumina-reinforced aluminum coating was deposited on the Ti6Al4V substrate by cold spraying. The CS-coating was employed by using a mixture of $40 \mathrm{wt} . \%$ $\alpha-\mathrm{Al}_{2} \mathrm{O}_{3}$ powder and $60 \mathrm{wt} . \%$ aluminum powder. Cold spraying was conducted by a low-pressure cold spray machine (LP-TCY-II, Tianchengyu, Beijing, China). Compressed air was used as the process gas, the working pressure was maintained at $0.8 \mathrm{MPa}$, the distance from the nozzle to the substrate was $10 \mathrm{~mm}$, and the traverse speed of the nozzle during spraying was $5 \mathrm{~mm} / \mathrm{s}$. The thickness of the CS-coating was $500 \pm 30 \mu \mathrm{m}$, as shown in Figure 1.

Table 1. Chemical composition of the Ti6Al4V alloy (wt. \%).

\begin{tabular}{ccccc}
\hline Al & V & O & Fe & Ti \\
\hline $5.5 \sim 6.9$ & $3.5 \sim 4.5$ & $<0.2$ & $<0.4$ & balance \\
\hline
\end{tabular}




\section{Carbon conductive tape}

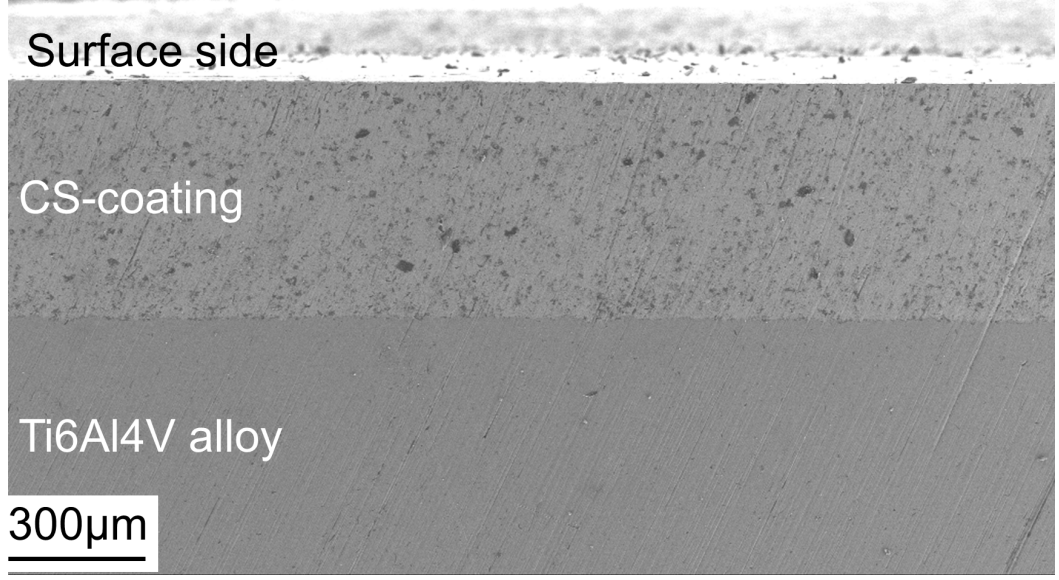

Figure 1. Cross-sectional morphology of Ti6Al4V alloy with CS-coating.

Specimens of size $20 \times 20 \times 5 \mathrm{~mm}^{3}$ were cut from the Ti6Al4V plate with and without CS-coating using a wire cut electrical discharge machine. Prior to the PEO process, each specimen was connected to a copper wire and then mounted in epoxy resin to provide a $20 \times 20 \mathrm{~mm}^{2}$ working area. The working surfaces of the specimens were successively wet-ground up to 1500 grit using emery abrasive papers, rinsed in distilled water, and dried in air.

\subsection{Coatings Preparation and Process Parameters}

A 750 V/5 A power source (NHWYM750-5, Jinannenghua, Jinan, China) was employed for applying the pulsed wave forms during the PEO treatment. A $10 \mathrm{~L}$ stainless container equipped with magnetic stirring and cooling system was used as cathode. The electrolyte temperature was kept at $30 \pm 5^{\circ} \mathrm{C}$.

For the Ti6Al4V specimens with CS-coating, the PEO process was performed under galvanostatic conditions in electrolyte containing $5 \mathrm{~g} / \mathrm{L} \mathrm{Na}_{2} \mathrm{SiO}_{3}$ and $1 \mathrm{~g} / \mathrm{L} \mathrm{KOH}$. Two types of current modes were employed: a soft sparking mode and a unipolar mode. In the soft sparking mode, the anodic and cathodic currents were set at 30 and $33.33 \mathrm{~A} / \mathrm{dm}^{2}$, respectively, leading to a ratio of $Q p / Q n=0.9$. In unipolar mode, the anodic current was set at $30 \mathrm{~A} / \mathrm{dm}^{2}$. Details of process parameters are given in Table 2. The PEO samples processed under soft sparking mode and unipolar mode were coded as S1 and S2, respectively.

Table 2. PEO process parameters for Ti6Al4V alloy with CS-coating.

\begin{tabular}{cccccccccc}
\hline $\begin{array}{c}\text { Sample } \\
\text { Code }\end{array}$ & Mode & $\begin{array}{c}\text { Time } \\
(\mathbf{s})\end{array}$ & $\mathbf{I}^{+}(\mathbf{A})$ & $\mathbf{I}^{-}(\mathbf{A})$ & $\begin{array}{c}\mathrm{T}_{\text {on }}^{+} \\
(\boldsymbol{\mu s})\end{array}$ & $\begin{array}{c}\mathrm{T}_{\text {off }}^{+} \\
(\boldsymbol{\mu} \mathbf{s})\end{array}$ & $\begin{array}{c}\mathrm{T}_{\text {on }}^{-} \\
(\boldsymbol{\mu s})\end{array}$ & $\begin{array}{c}\mathrm{T}_{\text {off }}^{-} \\
(\boldsymbol{\mu s})\end{array}$ & $\boldsymbol{Q}_{p} / \boldsymbol{Q}_{n}$ \\
\hline S1 & $\begin{array}{c}\text { Soft sparking } \\
\text { unipolar }\end{array}$ & 1320 & 1.2 & 1.33 & 900 & 100 & 900 & 100 & 0.9 \\
S2 & 1320 & 1.2 & N/A & 900 & 1100 & N/A & N/A & $\infty$ \\
\hline
\end{tabular}

As a reference, Ti6Al4V alloy without CS-coating was also subjected to PEO treatment, and the sample was coded as S3. The PEO treatment was carried out under constant anodic voltage of $350 \mathrm{~V}$ and cathodic voltage of $60 \mathrm{~V}$ in an electrolyte comprising $10 \mathrm{~g} / \mathrm{L}$ $\mathrm{Na}_{2} \mathrm{SiO}_{3}, 3 \mathrm{~g} / \mathrm{L} \mathrm{KOH}$, and $4 \mathrm{~g} / \mathrm{L} \mathrm{NaH}_{2} \mathrm{PO}_{4}$. Table 3 lists the PEO process parameters for the Ti6Al4V alloy. 
Table 3. PEO process parameters for Ti6Al4V alloy without CS-coating.

\begin{tabular}{cccccccc}
\hline Sample Code & Time $(\mathbf{s})$ & $\mathrm{U}^{+}(\mathrm{V})$ & $\mathrm{U}^{-}(\mathrm{V})$ & $\mathrm{T}_{\mathrm{ON}}^{+}(\mu \mathrm{s})$ & $\mathrm{T}_{\text {off }}^{+}(\mu \mathrm{s})$ & $\mathrm{T}_{\text {on }}^{-}(\mu \mathrm{s})$ & $\mathrm{T}_{\text {off }}^{-}(\mu \mathrm{s})$ \\
\hline S3 & 1020 & 350 & 60 & 900 & 100 & 900 & 100 \\
\hline
\end{tabular}

\subsection{Characterization Methods}

The surfaces and the cross-sections of samples were examined using a scanning electron microscope (SEM, GeminiSEM 300, Carl Zeiss, Jena, Germany). An X-ray diffraction system (XRD, D8 advance, Bruker, Karlsruhe, Germany) was used to characterize the phase composition of the $\mathrm{PEO}$ coatings $(\mathrm{Cu} \mathrm{K} \alpha$ radiation, accelerating voltage $40 \mathrm{kV}$, current $15 \mathrm{~mA}$, scanning speed $20^{\circ} / \mathrm{min}$, step size $0.02^{\circ}$, and scan range of $20^{\circ}-100^{\circ}$ ). A Vickers hardness tester (HX-1000TM, Baoleng, Shanghai, China) was employed to measure the cross-sectional hardness of the PEO coatings with a load of $100 \mathrm{~g}$ and dwelling time of 15 s. An eddy current thickness meter (TT230, Beijing, China) was used to determine the thickness of the PEO coatings. The wear resistance of the Ti6Al4V alloy with and without PEO coatings were evaluated by a high-speed reciprocating friction tester (HSR-2M, Zhongkekaihua, Lanzhou, China). A ball (WC-6Co material, $6 \mathrm{~mm}$ in diameter) was pressed against the surface of the specimen under the load of $4.9 \mathrm{~N}$ for reciprocating motion. The travel distance was $4 \mathrm{~mm}$, the reciprocating frequency was $5 \mathrm{~Hz}$, and the wear test lasted for $30 \mathrm{~min}$. Coefficients of friction (COF) were recorded during the sliding tests. After the sliding tests, a laser confocal microscope (OLS4000, Olympus, Tokyo, Japan) was used to measure the morphologies and depth profiles of the wear tracks. The cross-sectional area of wear tracks was obtained from the Olympus control software. Wear rates of specimens were calculated using the following equation [24]:

$$
\omega=l \times S /(N \times L)
$$

where $\omega$ is wear rate, $\mathrm{mm}^{3} /(\mathrm{Nm}) ; l$ is length of wear track, $\mathrm{mm}$; $S$ is cross sectional area of wear track, $\mathrm{mm}^{2} ; \mathrm{N}$ is load, $\mathrm{N}$; and $L$ is sliding distance, $\mathrm{m}$.

\section{Results and Discussion}

\subsection{The Cell Voltage-Time and Current Density-Time Responses during PEO Treatment}

The anodic voltage-versus-time plot during PEO of the Ti6Al4V alloy with CS-coating is shown in Figure 2. The curves for samples processed under soft sparking mode and unipolar mode both consisted of three stages. At stage I, an abrupt linear increase in voltage was observed within a short period of time. This stage was similar to conventional anodization which involved the rapid formation of an initial thin oxide film. At the end of stage I, the dielectric breakdown of the oxide film occurred.

At stage II, a large number of yellow discharges were observed, covering the entire surface of the sample evenly for both sample S1 and sample S2. The voltage kept increasing slowly and reached to $540 \mathrm{~V}$ and $587 \mathrm{~V}$ at the end of section II for samples S1 and S2, respectively. For sample S1, at about 540 s, tiny white-blue discharges were observed, preferentially starting at edges of the sample, then moving towards the center with increasing time. After all the surface was covered by the white-blue discharges, the voltage tended to decrease. In the meantime, the light and sound produced by the discharges became weaker. All these phenomena indicated that the PEO process gradually transited to the soft sparking regime [25].

At stage III, for sample S1, the anodic voltage decreased from 540 to $420 \mathrm{~V}$. White-blue discharges covered the whole area around the specimen at a high population density. For sample S2, the discharges became more intense, their color changed gradually from yellow to orange, and the voltage increased to $622 \mathrm{~V}$ at the end of the test. 


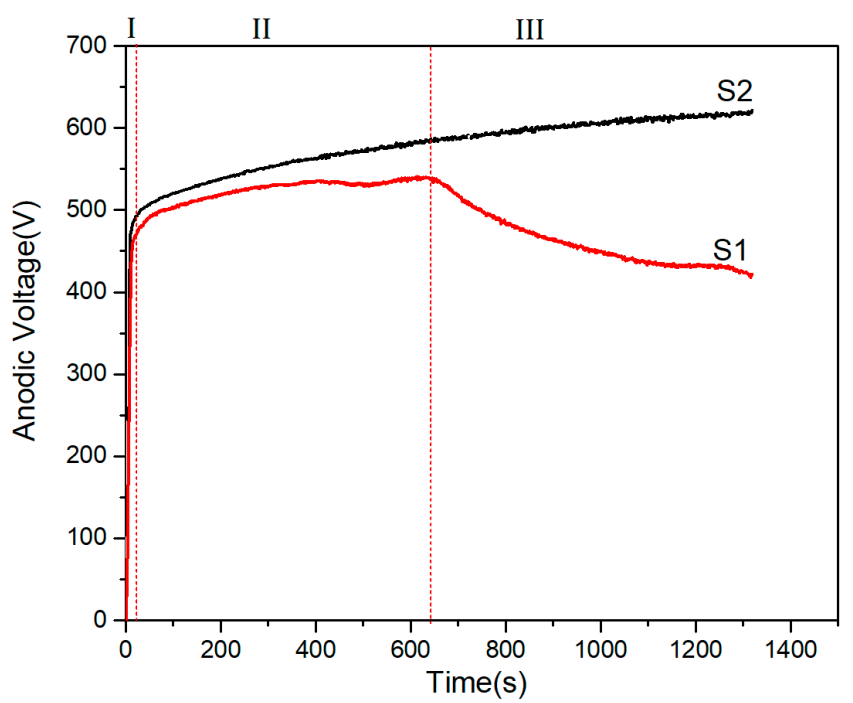

Figure 2. Anodic voltage-time response during PEO of Ti6Al4V alloy with CS-coating using soft sparking mode and unipolar mode.

Figure 3 shows the cell current density-versus-time curve recorded during PEO treatment of Ti6Al4V alloy. In the first stage $(0-5 \mathrm{~s})$, the current density increased linearly with a very steep slope. This stage corresponded to the anodization process which developed a thin passive film via oxidation of the metal surface. At the second stage (6-100 s), micro-discharges were started due to the high applied electrical field. At this stage, the current density decreased quickly with time, due to the formation of a dense and thick oxide layer. The formation of the oxide layer increased the electrical resistance at the substrate/electrolyte interface and, hence, decreased the current density according to Ohm's law. At stage III (100-1020 s), the current density decreased slowly, reaching $0.1 \mathrm{~A}$ at the end of the process. During this stage, sparks scanned the entire sample surface, leading to the formation of the oxide layer.

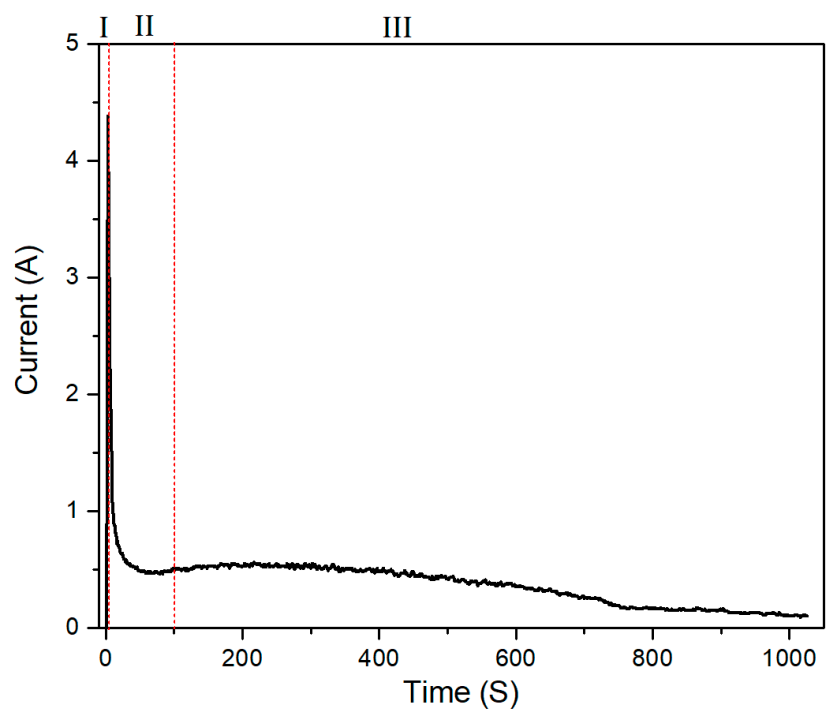

Figure 3. Cell current density-versus-time responses during PEO treatments of the Ti6Al4V alloy.

\subsection{Morphology of Coatings}

Figure 4 compared the surface and cross-section morphologies of the samples processed under different conditions. Figure 4a shows the surface morphology of the PEO coating formed on sample S1. The use of the soft sparking mode resulted in the formation 
of a "sponge"-like structure with fine open pores. The pores were formed by the gas evolution during the PEO process. Figure $4 \mathrm{~b}$ showed the cross-section morphology of sample S1. Two distinct regions could be recognized from the figure, the inner CS-coating and the outer PEO coating. The CS-coating was compact with a thickness of about $220 \pm 5 \mu \mathrm{m}$, and some $\mathrm{Al}_{2} \mathrm{O}_{3}$ particles were clearly visible in the aluminum matrix. The thickness of the PEO coating was uniform with a value of $115 \pm 4 \mu \mathrm{m}$. The PEO coating could be subdivided into two layers, the outer porous layer and the inner dense layer, which was similar with the PEO coatings prepared on bulk aluminum alloys under soft sparking mode [26,27]. The outer layer was characterized by a number of interconnected tiny pores, while the inner layer exhibited a dense compact structure due to the reduction of long-lived and strong discharges by using the soft sparking mode. It is noteworthy that no $\mathrm{Al}_{2} \mathrm{O}_{3}$ particles were found in the $\mathrm{PEO}$ coating. The reason might be that the $\mathrm{Al}_{2} \mathrm{O}_{3}$ particles were melted and integrated into the PEO coating during the PEO process because the melting point of $\mathrm{Al}_{2} \mathrm{O}_{3}$ is $2072{ }^{\circ} \mathrm{C}$ [28] which could be reached within a few milliseconds at the location of micro discharges $[26,29]$.
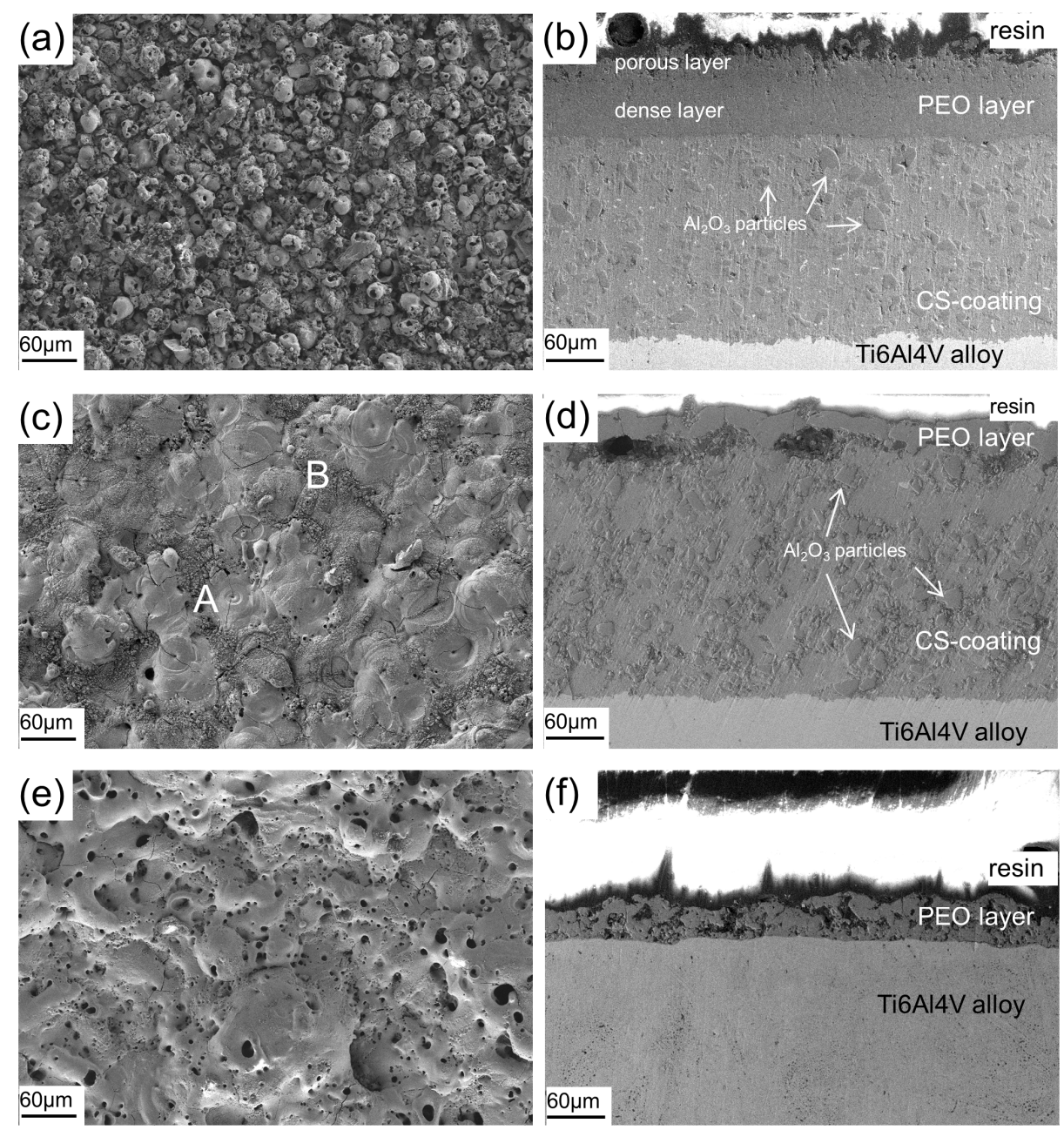

Figure 4. Surface morphologies of PEO coatings on samples: (a) S1; (c) S2; (e) S3; cross-section morphologies of samples: (b) S1; (d) S2; (f) S3.

The PEO coating formed under unipolar current mode showed a cracked pancake-like morphology (site " $\mathrm{A}$ " in Figure $4 \mathrm{~b}$ ) along with dispersed fine round particles (site " $\mathrm{B}$ " in Figure $4 \mathrm{~b}$ ). In the center of each pancake-like structure, a micropore was observed. The pancake-like structure was a typical feature of PEO coating on aluminum [8]. Figure $4 \mathrm{~d}$ showed the cross-section morphology of the coating. The thickness of the oxide scale was 
not so uniform with a value of $76 \pm 10 \mu \mathrm{m}$, much less than that formed under soft sparking mode. There were large cavities that appeared as a band beneath the PEO coating. The connected large cavities were developed by strong " $\mathrm{B}$ " type discharges as reported in Hussein's model [30] which caused melting and vaporizing of both the substrate alloy and the dielectric oxide layer. The molten materials erupted from discharge channels, and some gases were trapped in the coating/substrate interface layer, turning into cavities.

The surface and cross-section views of the PEO coating directly fabricated on the Ti6Al4V alloy are shown in Figure 4e,f, respectively. It can be seen from Figure 4e that there were large numbers of pores with different diameters along with few micro-cracks on the surface, which are typical characteristics of PEO coatings formed on titanium alloy [31,32]. It can be seen from the cross-section view that there were also many pores in the PEO coating, and the thickness of the PEO coating was $70 \pm 4 \mu \mathrm{m}$.

\subsection{Phase Composition of Coatings}

Figure 5a presents the XRD results of the PEO coatings prepared on Ti6Al4V alloy with CS-coating. For samples $\mathrm{S} 1$ and $\mathrm{S} 2$, the main phases in the oxide layer were $\alpha-\mathrm{Al}_{2} \mathrm{O}_{3}$ and $\gamma-\mathrm{Al}_{2} \mathrm{O}_{3}$. Figure $5 \mathrm{~b}$ presents the XRD result of the PEO coating directly fabricated on the Ti6Al4V alloy. The spectra revealed that the coating was mainly composed of rutile and the anatase, which was in agreement with the results given in literature $[33,34]$. The relative quantity of the $\alpha-\mathrm{Al}_{2} \mathrm{O}_{3}$ and $\gamma-\mathrm{Al}_{2} \mathrm{O}_{3}$ phases of samples $\mathrm{S} 1$ and $\mathrm{S} 2$ was semi-qualitatively compared by taking the height ratio of the (113) peak for $\alpha-\mathrm{Al}_{2} \mathrm{O}_{3}$ and (400) peak for $\gamma$ $\mathrm{Al}_{2} \mathrm{O}_{3}[35,36]$. The $\alpha-\mathrm{Al}_{2} \mathrm{O}_{3} / \gamma-\mathrm{Al}_{2} \mathrm{O}_{3}$ peak height ratios for samples $\mathrm{S} 1$ and $\mathrm{S} 2$ were 0.8955 and 0.7966 , respectively. The result indicated that relatively more $\alpha-\mathrm{Al}_{2} \mathrm{O}_{3}$ was formed by using the soft sparking mode. There were two possible reasons for this phenomenon. Firstly, the PEO coating formed under the soft sparking mode was relatively thicker and more compact than that formed under unipolar mode, which resulted in a lower thermal conductivity of the coating. The thermal energy could accumulate in the coating and induced a temperature rise high enough to cause the $\gamma \rightarrow \alpha-\mathrm{Al}_{2} \mathrm{O}_{3}$ phase transition [35]. Secondly, the hydrogen species generated during the cathodic period would provide 'seeds' for the $\gamma \rightarrow \alpha$ phase transition [27]. Another noticeable feature was that intense diffraction peaks of the $\mathrm{Al}$ phase were detected in sample S2. This was largely because the oxide layer formed on sample S2 was thin and porous. The CS-coating could be detected directly by X-rays. The Al phase diffraction peaks of sample S1 were too small to distinguish, demonstrating that the ceramic coating formed under soft sparking mode was thick and compact, which was consistent with Figure 4.

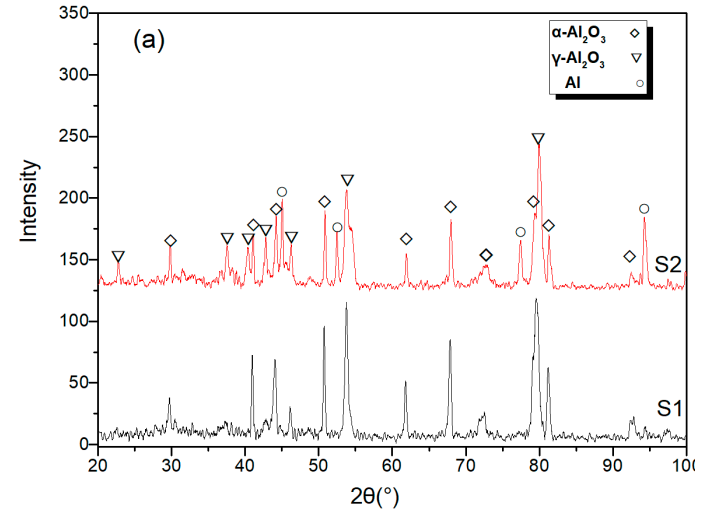

(a)

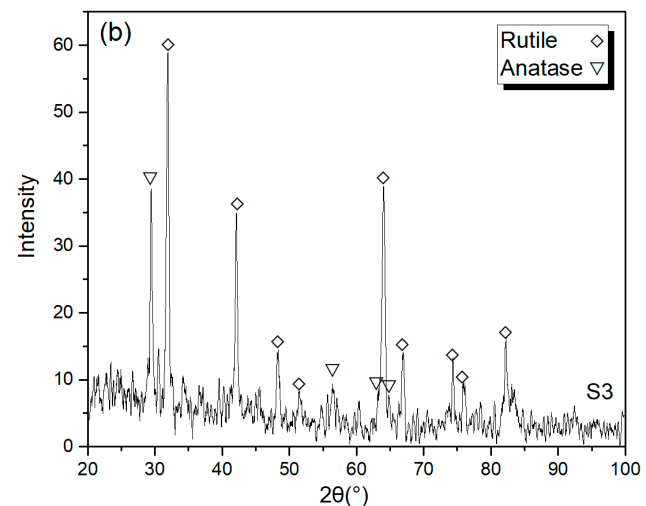

(b)

Figure 5. X-ray diffraction patterns of PEO coatings: (a) S1, S2; (b) S3.

\subsection{Micro Hardness of Coatings}

The microhardness values were measured on the cross-section of the PEO coatings. The average microhardness values of the PEO coating on samples S1, S2, and S3 were 
$1046 \pm 165 \mathrm{HV}_{0.1}, 783 \pm 281 \mathrm{HV}_{0.1}$, and $539 \pm 173 \mathrm{HV}_{0.1}$, respectively, as shown in Figure 6. The PEO coating of sample $\mathrm{S} 1$ exhibited much higher microhardness than the other two samples due to its compact structure and a large number of $\alpha-\mathrm{Al}_{2} \mathrm{O}_{3}$ phases. Figure 7 depicts the variation of cross-sectional microhardness of sample $\mathrm{S} 1$ as a function of distance from the Ti6Al4V substrate/CS-coating interface. The microhardness values of the Ti6Al4V substrate and the CS-coating were $346 \pm 5 \mathrm{HV}_{0.1}$ and $107 \pm 6 \mathrm{HV}_{0.1}$, respectively. The microhardness of the PEO coating increased first and then decreased with increasing distance from the CS-coating/PEO coating interface. The variation in hardness along the coating thickness could be explained by the change of phase composition and microstructure of the PEO coating. During the PEO process of the aluminum alloy, the PEO coating grew towards the side of the aluminum alloy, and the aluminum first oxidized to $\gamma-\mathrm{Al}_{2} \mathrm{O}_{3}[37,38]$. Afterwards, a successive transformation from $\gamma-\mathrm{Al}_{2} \mathrm{O}_{3}$ to $\alpha-\mathrm{Al}_{2} \mathrm{O}_{3}$ occurred due to the high temperature around the plasma discharge channels. This led to the relative high $\gamma-\mathrm{Al}_{2} \mathrm{O}_{3}$ content at the bottom of the PEO coating and the enrichment of $\alpha-\mathrm{Al}_{2} \mathrm{O}_{3}$ in the middle region of the PEO coating [27,37]. Since the hardness values of the $\gamma-\mathrm{Al}_{2} \mathrm{O}_{3}$ and $\alpha-\mathrm{Al}_{2} \mathrm{O}_{3}$ phase are 806 and $2183 \mathrm{HV}$, respectively [39], it was found that the middle region of the PEO coating was harder than the bottom region. The measurement of low hardness values close to the outermost regions could be attributed to the high micro-porosity concentration as shown in Figure $4 \mathrm{~b}$.

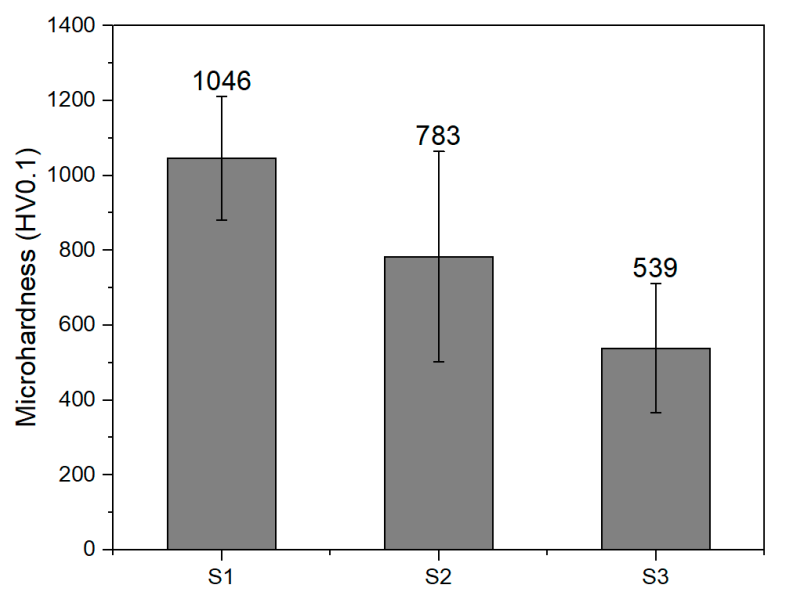

Figure 6. Microhardness of PEO coatings on samples S1, S2, S3.

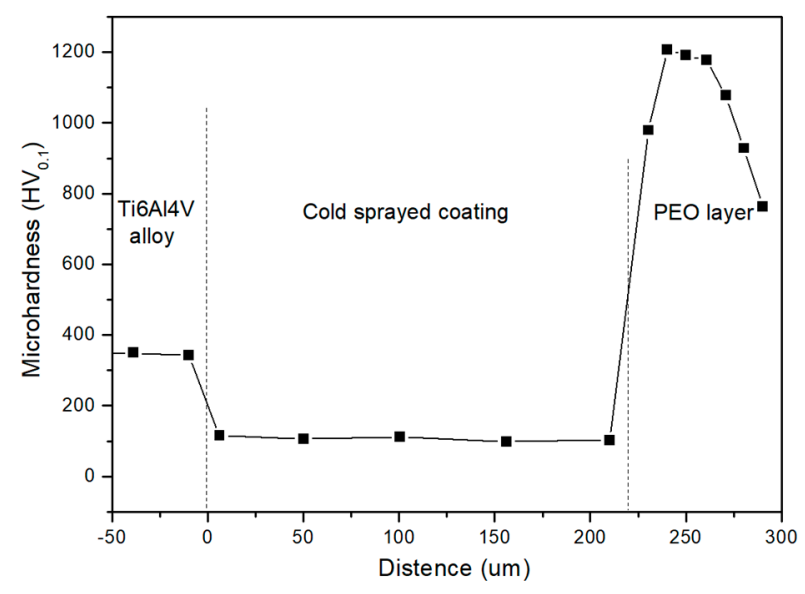

Figure 7. Cross-sectional microhardness of sample $\mathrm{S} 1$ as a function of the distance from the Ti6Al4V substrate/CS-coating interface. 


\subsection{Wear Test}

\subsubsection{Coefficients of Friction (COF)}

Figure 8 shows the COF versus time of samples worn under a load of $4.9 \mathrm{~N}$. As can be seen from the result, the COF of sample S1 increased rapidly at the initial $4.0 \mathrm{~min}$ of the wear test, corresponding to the wearing off the outer loose layer. After that, the COF maintained at a steady range from 0.27 to 0.30 due to the decrease of the PEO coating roughness. For sample $\mathrm{S} 2$, the $\mathrm{COF}$ increased rapidly at the first $10 \mathrm{~min}$ of the test and then kept increasing slowly to 0.31 for the remaining time of the test. The COF changing trend of sample S3 was similar to that of sample S1, increased quickly at the beginning of the test and then maintained at a steady value, except that the oscillation was serious. The COF of the uncoated Ti6Al4V alloy was lower than the samples with PEO coatings. During the test, the COF gradually increased from 0.14 to 0.24 and was accompanied by severe oscillation. The oscillation of COF suggested that the tribological behavior of the uncoated Ti6Al4V alloy was poor, although the COF was not very high.

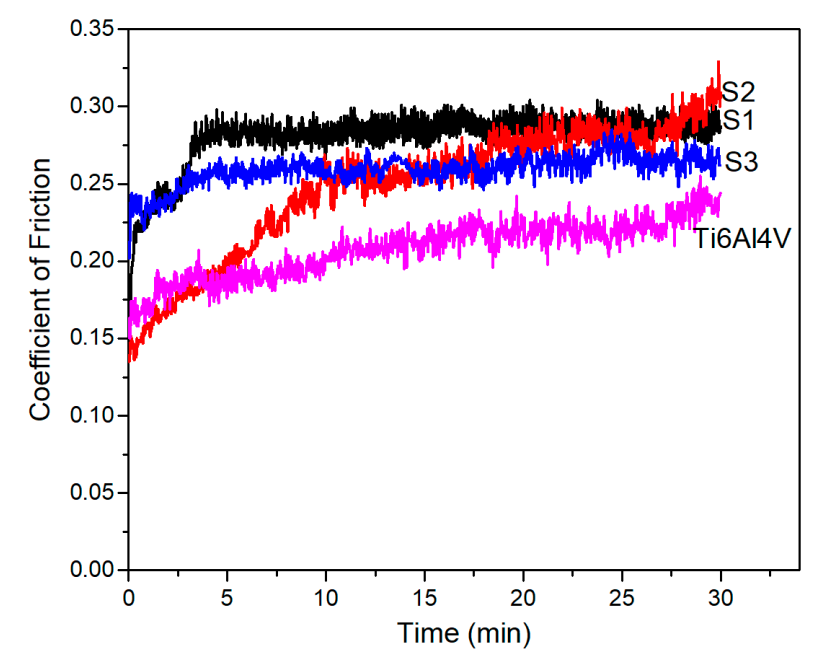

Figure 8. The variation of COF versus time of coated and uncoated Ti6Al4V alloy.

\subsubsection{Friction Morphology}

The 3D morphologies of the wear tracks for the coated and uncoated Ti6Al4V alloy were shown in Figure 9a-d, respectively, and the depth profiles of the wear tracks are shown in Figure 9e. It can be seen from Figure 9a that the wear track of the sample S1 was quite smooth and showed no evidence of detachment of the PEO coating, indicating that the mechanism of the wear was mainly abrasive wear. The width and depth of the wear track were the lowest of the four wear tracks, revealing an excellent wear performance of the PEO coating. It can be seen from Figure $9 b$ that the wear track of sample S2 was much wider (around $1290.3 \mu \mathrm{m}$ ) and deeper (more than $56.4 \mu \mathrm{m}$ ) compared to sample S1. It is worth noting that many spalled pits appeared on the wear track, which increased the roughness of the wear track and led to a high COF. The formation of pits was caused by the detachment of the PEO coating during the sliding test. As shown in Figure 4d, the PEO coating formed under unipolar mode was thin and cracked, and there were large cavities beneath the PEO coating. During the sliding test, the PEO coating was easily fractured and peeled off, as it was brittle and the bonding force between the PEO coating and the CS-coating was weak. Therefore, abrasive wear and brittle fractures were the main wear damage for the PEO coating formed on sample S2. The wear track of sample S3 was smoother than that of sample S2; however, a few pits were also found on the wear track, indicating that a part of bulk oxides had peeled off. The width and depth of the wear track of sample S3 were larger than those of sample S1, as the pores in the PEO coating reduced the coating load bearing capacity. The wear track of the uncoated Ti6Al4V substrate was much wider and deeper than the coated samples, as shown in Figure 9d,e. 
The morphology of the wear track exhibited deep scratches and large deformations, similar to results reported in literature $[40,41]$. This could be attributed to the low hardness and high plasticity of the TC4 alloy, which made it deform easily and generate material loss under repeated force.
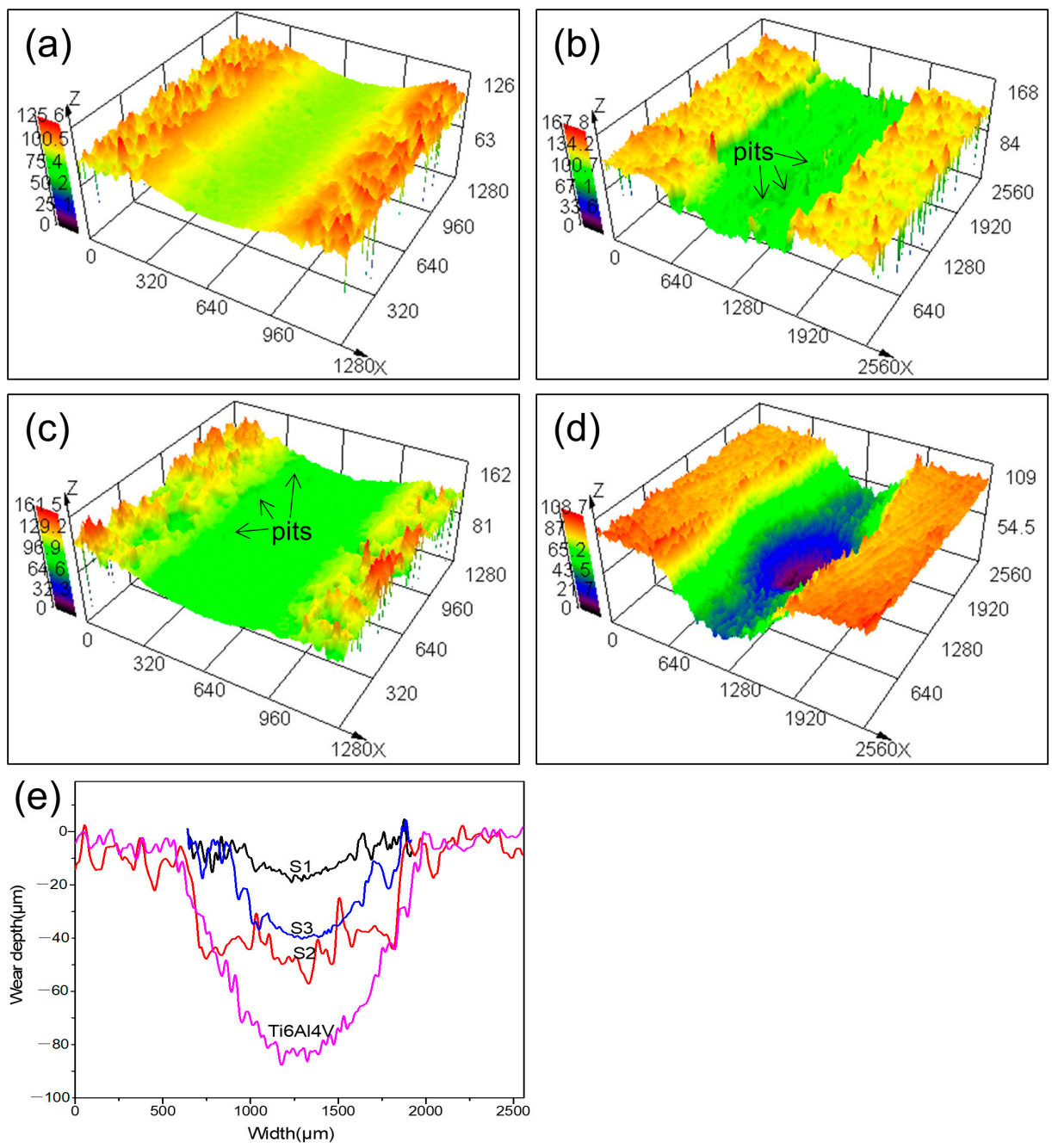

Figure 9. 3D morphology of wear tracks on different samples (a) S1; (b) S2; (c) S3; (d) Ti6A14V substrate; (e) cross-sectional profiles of wear tracks.

\subsubsection{Wear Rate}

The average wear rates of samples S1, S2, and S3 and uncoated Ti6Al4V alloy were calculated to be $1.18 \times 10^{-5}, 5.72 \times 10^{-5}, 3.57 \times 10^{-5}$, and $7.72 \times 10^{-5} \mathrm{~mm}^{3} /(\mathrm{Nm})$, respectively, as shown in Figure 10. Sample S1 exhibited the lowest wear rate, which was only $15.28 \%$ of that of the Ti6Al4V substrate. The excellent wear resistance of the coating depended on both the phase constituents and the structures of the coatings. On the one hand, the PEO coating that formed on sample $\mathrm{S} 1$ was mainly composed of $\mathrm{Al}_{2} \mathrm{O}_{3}$ and had a higher content of $\alpha-\mathrm{Al}_{2} \mathrm{O}_{3}$ than sample S2. The average hardness of the oxide layer that formed on sample S1 was higher than those that formed on samples S2 and S3. According to Archard's wear law [42]:

$$
\omega=K \frac{L}{H}
$$

where $\omega$ is the wear rate, $K$ is the wear coefficient, $L$ is the applied pressure, and $H$ is the hardness of the material. The higher the hardness of a coating, the lower the wear loss obtained. On the other hand, the excellent wear resistance of the PEO coating depended on its micro-structure. The PEO coating that formed on sample S1 was more compact than the 
one that formed on samples S2 and S3, as can be seen in Figure 4, resulting in an excellent load bearing capacity of the coating.

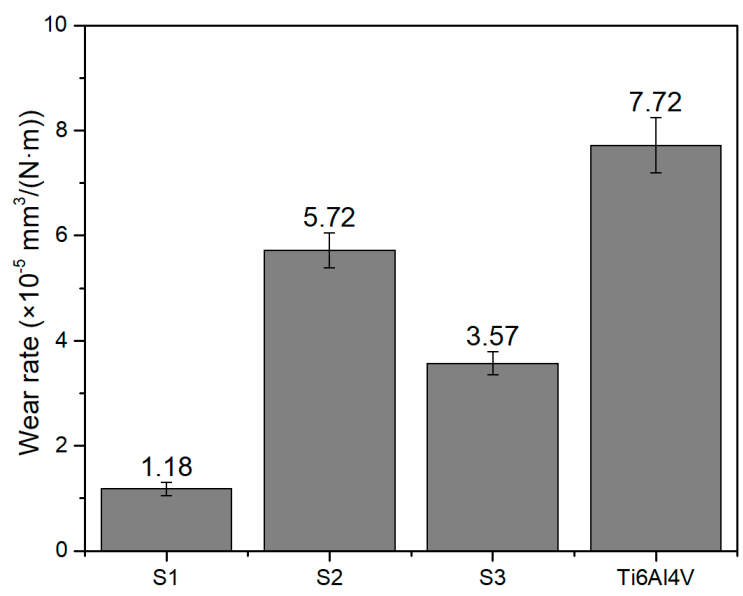

Figure 10. Wear rates of coated and uncoated Ti6Al4V alloy.

The investigations indicated that the combination of cold spraying and PEO under soft sparking mode was a promising technique for improving the wear resistance of the Ti6Al4V alloy. It should be pointed out that one advantage of this combination treatment was that both the cold spray process and the PEO process were carried out under very low temperatures of no more than $200{ }^{\circ} \mathrm{C}$. Therefore, the combination treatment had little thermal effect on the substrate alloy. Another thing that needs to be pointed out is that although the wear rate of S1 was low, the COF was still relatively high, as shown in Figure 8. Further research is needed to reduce the COF of the PEO coating formed under soft sparking mode, which can further increase the wear resistance of the PEO coating.

\section{Conclusions}

In this study, Ti6Al4V alloy with and without CS-coating was subjected to PEO treatment in order to prepare wear-resistant PEO coatings. The PEO treatment of the Ti6Al4V alloy with CS-coating was processed under soft sparking mode and unipolar mode, respectively. The following results were obtained:

(1) The PEO coating that formed on the Ti6Al4V alloy with CS-coating under soft sparking mode had a more compact structure, relatively higher $\alpha-\mathrm{Al}_{2} \mathrm{O}_{3}$ content, and higher micro hardness than that formed under unipolar mode.

(2) The PEO coating that formed on Ti6Al4V base alloy was mainly composed of $\mathrm{TiO}_{2}$ and contained cracks and pores.

(3) Among all the samples, the PEO coating that formed on CS-coating under soft sparking mode exhibited the best wear resistance with a wear rate of $1.18 \times 10^{-5} \mathrm{~mm}^{3} /(\mathrm{Nm})$. The excellent wear resistance of the coating depended on the higher $\alpha-\mathrm{Al}_{2} \mathrm{O}_{3}$ content and compact structure of the coating.

(4) The investigations indicated that the combination of cold spraying and PEO under soft sparking mode is a promising technique for improving the wear resistance of titanium alloys. Further research is needed to reduce the COF of the PEO coating formed under soft sparking mode.

Author Contributions: Conceptualization, M.S. and W.W.; methodology, M.S.; data curation, X.Z.; writing—original draft, M.S.; writing—review and editing, W.W. and H.Y.; funding acquisition, M.S. supervision, X.H. All authors have read and agreed to the published version of the manuscript.

Funding: This research was funded by Special Research Project of Shaanxi Provincial Department of Education (No. 18JK0475), and Shaanxi Provincial Natural Science Foundation (No. 2020JM-493). 
Institutional Review Board Statement: Not applicable.

Informed Consent Statement: Not applicable.

Data Availability Statement: Data is contained within the article.

Conflicts of Interest: The authors declare no conflict of interest.

\section{References}

1. Leyens, C.; Peters, M. Titanium and Titanium Alloys: Fundamentals and Applications; Wiley-VCH: Weinheim, Germany, 2003; pp. 19-22.

2. Boyer, R.R. An overview on the use of titanium in the aerospace industry. Mater. Sci. Eng. A-Struct. 1996, 213, 103-114. [CrossRef]

3. Zhang, T.G.; Zhuang, H.F.; Zhang, Q.; Yao, B.; Yang, F. Influence of $\mathrm{Y}_{2} \mathrm{O}_{3}$ on the microstructure and tribological properties of Ti-based wear-resistant laser-clad layers on TC4 alloy. Ceram. Int. 2020, 46, 13711-13723. [CrossRef]

4. Li, X.; Hu, G.; Tian, J.; Tian, W.; Xie, W.; Li, X. Wear resistance enhancement of Ti-6Al-4 V Alloy by applying Zr-modified silicide coatings. J. Mater. Eng. Perform. 2018, 27, 1073-1082. [CrossRef]

5. Jin, J.; Duan, H.; Li, X. The influence of plasma nitriding on microstructure and properties of CrN and CrNiN coatings on Ti6Al4V by magnetron sputtering. Vacuum 2017, 136, 112-120. [CrossRef]

6. Liu, W.; Blawert, C.; Zheludkevich, M.L.; Lin, Y.; Talha, M.; Shi, Y.; Chen, L. Effects of graphene nanosheets on the ceramic coatings formed on Ti6Al4V alloy drill pipe by plasma electrolytic oxidation. J. Alloy Compd. 2019, 789, 996-1007. [CrossRef]

7. Mu, M.; Liang, J.; Zhou, X.; Xiao, Q. One-step preparation of $\mathrm{TiO}_{2} / \mathrm{MoS}_{2}$ composite coating on Ti6Al4V alloy by plasma electrolytic oxidation and its tribological properties. Surf. Coat. Tech. 2013, 214, 124-130. [CrossRef]

8. Kaseem, M.; Fatimah, S.; Nashrah, N.; Ko, Y.G. Recent progress in surface modification of metals coated by plasma electrolytic oxidation: Principle, structure, and performance. Prog. Mater. Sci. 2021, 117, 100735. [CrossRef]

9. Bailing, J.; Yaming, W. Plasma electrolytic oxidation treatment of aluminium and titanium alloys. In Surface Engineering of Light Alloys; Dong, H., Ed.; Woodhead Publishing: Cambridge, UK, 2010; Volume 5, pp. 110-154.

10. Fazel, M.; Salimijazi, H.R.; Golozar, M.A.; Garsivaz Jazi, M.R. A comparison of corrosion, tribocorrosion and electrochemical impedance properties of pure Ti and Ti6Al4V alloy treated by micro-arc oxidation process. Appl. Surf. Sci. 2015, 324, 751-756. [CrossRef]

11. Qin, Y.K.; Xiong, D.S.; Li, J.L.; Tyagi, R. Compositions and tribological properties of PEO coatings on Ti6Al4V alloy. Surf. Eng. 2017, 33, 895-902. [CrossRef]

12. Bertuccioli, C.; Garzoni, A.; Martini, C.; Morri, A.; Rondelli, G. Plasma electrolytic oxidation (PEO) layers from silicate/phosphate baths on Ti-6Al-4V for biomedical components: Influence of deposition conditions and surface finishing on dry sliding behaviour. Coatings 2019, 9, 614. [CrossRef]

13. Simchen, F.; Sieber, M.; Kopp, A.; Lampke, T. Introduction to plasma electrolytic oxidation-an overview of the process and applications. Coatings 2020, 10, 628. [CrossRef]

14. Tsai, D.; Chen, G.; Chou, C. Probe the micro arc softening phenomenon with pulse transient analysis in plasma electrolytic oxidation. Surf. Coat. Technol. 2019, 357, 235-243. [CrossRef]

15. Rogov, A.B.; Yerokhin, A.; Matthews, A. The role of cathodic current in plasma electrolytic oxidation of aluminum: Phenomenological concepts of the "soft sparking" mode. Langmuir 2017, 33, 11059-11069. [CrossRef]

16. Hakimizad, A.; Raeissi, K.; Santamaria, M.; Asghari, M. Effects of pulse current mode on plasma electrolytic oxidation of $7075 \mathrm{Al}$ in $\mathrm{Na}_{2} \mathrm{WO}_{4}$ containing solution: From unipolar to soft-sparking regime. Electrochim. Acta 2018, 284, 618-629. [CrossRef]

17. Koshuro, V.A.; Fomina, M.A.; Rodionov, I.V.; Fomin, A.A. Nanoporous structure of coatings formed by thermal spraying of aluminum oxide with further microarc oxidation on titanium alloy VT6 implants. Biomed. Eng. 2016, 50, 54-57. [CrossRef]

18. Koshuro, V.; Fomin, A.; Rodionov, I. Composition, structure and mechanical properties of metal oxide coatings produced on titanium using plasma spraying and modified by micro-arc oxidation. Ceram. Int. 2018, 44, 12593-12599. [CrossRef]

19. Kang, S.; Tu, W.; Han, J.; Li, Z.; Cheng, Y. A significant improvement of the wear resistance of Ti6Al4V alloy by a combined method of magnetron sputtering and plasma electrolytic oxidation (PEO). Surf. Coat. Technol. 2019, 358, 879-890. [CrossRef]

20. Hu, C.; Chiu, P. Wear and corrosion resistance of pure titanium subjected to aluminization and coated with a microarc oxidation ceramic coating. Int. J. Electrochem. Sci. 2015, 10, 4290-4302.

21. Moridi, A.; Hassani-Gangaraj, S.M.; Guagliano, M.; Dao, M. Cold spray coating: Review of material systems and future perspectives. Surf. Eng. 2014, 30, 369-395. [CrossRef]

22. Huang, G.; Wang, H.; Li, X.; Xing, L.; Zhou, J. Deposition efficiency of low pressure cold sprayed aluminum coating. Mater. Manuf. Process. 2018, 33, 1100-1106. [CrossRef]

23. Choi, W.B.; Li, L.; Luzin, V.; Neiser, R.; Gnäupel-Herold, T.; Prask, H.J.; Sampath, S.; Gouldstone, A. Integrated characterization of cold sprayed aluminum coatings. Acta Mater. 2007, 55, 857-866. [CrossRef]

24. Mi, P.; Zhao, H.; Wang, T.; Ye, F. Sliding wear behavior of HVOF sprayed WC-(nano-WC-Co) coating at elevated temperatures. Mater. Chem. Phys. 2018, 206,1-6. [CrossRef]

25. Tsai, D.; Chou, C. Review of the soft sparking issues in plasma electrolytic oxidation. Metals 2018, 8, 105. [CrossRef] 
26. Martin, J.; Nominé, A.; Ntomprougkidis, V.; Migot, S.; Bruyère, S.; Soldera, F.; Belmonte, T.; Henrion, G. Formation of a metastable nanostructured mullite during plasma electrolytic oxidation of aluminium in "soft" regime condition. Mater. Des. 2019, 180, 107977. [CrossRef]

27. Rogov, A.B.; Matthews, A.; Yerokhin, A. Role of cathodic current in plasma electrolytic oxidation of Al: A quantitative approach to in-situ evaluation of cathodically induced effects. Electrochim. Acta 2019, 317, 221-231. [CrossRef]

28. Patnaik, P. Handbook of Inorganic Chemicals; McGraw-Hill Professional: New York, NY, USA, 2002; pp. 11-12.

29. Hussein, R.O.; Nie, X.; Northwood, D.O. Effect of current mode on the plasma discharge, microstructure and corrosion resistance of oxide coatings produced on 1100 aluminum alloy by plasma electrolytic oxidation. WIT Trans. Eng. Sci. 2019, 124, 3-16.

30. Hussein, R.O.; Nie, X.; Northwood, D.O.; Yerokhin, A.; Matthews, A. Spectroscopic study of electrolytic plasma and discharging behaviour during the plasma electrolytic oxidation (PEO) process. J. Phys. D 2010, 43, 105203. [CrossRef]

31. Kumari, R.; Blawert, C.; Majumdar, J.D. Microstructures and properties of plasma electrolytic oxidized Ti alloy (Ti-6Al-4V) for bio-implant application. Metall. Mater. Trans. A Phys. Metall. Mater. Sci. 2016, 47, 788-800. [CrossRef]

32. Ríos, J.M.; Quintero, D.; Castaño, J.G.; Echeverría, F.; Gómez, M.A. Comparison among the lubricated and unlubricated tribological behavior of coatings obtained by PEO on the Ti6Al4V alloy in alkaline solutions. Tribol. Int. 2018, 128, 1-8. [CrossRef]

33. Tekin, K.C.; Malayoglu, U.; Shrestha, S. Tribological behaviour of plasma electrolytic oxide coatings on Ti6Al4V and cp-Ti alloys. Surf. Eng. 2016, 32, 435-442. [CrossRef]

34. Wheeler, J.M.; Collier, C.A.; Paillard, J.M.; Curran, J.A. Evaluation of micromechanical behaviour of plasma electrolytic oxidation (PEO) coatings on Ti-6Al-4V. Surf. Coat. Technol. 2010, 204, 3399-3409. [CrossRef]

35. Dehnavi, V.; Liu, X.Y.; Luan, B.L.; Shoesmith, D.W.; Rohani, S. Phase transformation in plasma electrolytic oxidation coatings on 6061 aluminum alloy. Surf. Coat. Technol. 2014, 251, 106-114. [CrossRef]

36. Cheng, Y.; Cao, J.; Mao, M.; Peng, Z.; Skeldon, P.; Thompson, G.E. High growth rate, wear resistant coatings on an Al-Cu-Li alloy by plasma electrolytic oxidation in concentrated aluminate electrolytes. Surf. Coat. Technol. 2015, 269, 74-82. [CrossRef]

37. Sieber, M.; Simchen, F.; Morgenstern, R.; Scharf, I.; Lampke, T. Plasma electrolytic oxidation of high-strength aluminium alloys-substrate effect on wear and corrosion performance. Metals 2018, 8, 356. [CrossRef]

38. Wu, Y.-k.; Yang, Z.; Wang, R.-q.; Wu, G.-r.; Chen, D.; Wang, D.-d.; Liu, X.-t.; Li, D.-1.; Guo, C.-h.; Yu, S.-x.; et al. An investigation of microstructure evolution for plasma electrolytic oxidation (PEO) coated $\mathrm{Al}$ in an alkaline silicate electrolyte. Surf. Coat. Technol. 2018, 351, 136-152. [CrossRef]

39. Krishna, L.R.; Gupta, P.S.V.N.; Sundararajan, G. The influence of phase gradient within the micro arc oxidation (MAO) coatings on mechanical and tribological behaviors. Surf. Coat. Technol. 2015, 269, 54-63. [CrossRef]

40. Benea, L.; Mardare-Danaila, E.; Celis, J. Increasing the tribological performances of Ti-6Al-4V alloy by forming a thin nanoporous $\mathrm{TiO}_{2}$ layer and hydroxyapatite electrodeposition under lubricated conditions. Tribol. Int. 2014, 78, 168-175. [CrossRef]

41. Yetim, A.F.; Yildiz, F.; Vangolu, Y.; Alsaran, A.; Celik, A. Several plasma diffusion processes for improving wear properties of Ti6Al4V alloy. Wear 2009, 267, 2179-2185. [CrossRef]

42. Archard, J.F. Contact and rubbing of flat surfaces. J. Appl. Phys. 1953, 24, 981-988. [CrossRef] 